\title{
CORRESPONDENCE
}

\section{Weber's Waves}

SIR,--I feel impelled to write about the report on the Oxford-CambridgeLondon Relativity Seminar (Nature, 243, $61 ; 1973$ ), as the account contains several inaccuracies and might give someone unfamiliar with the current experiments on gravitational radiation some misleading impressions. The reporter seems to have drawn the conclusion that it has already been shown that Weber's gravitational wave detectors are not detecting gravitational waves when in fact this degree of finality goes rather beyond the implications of currently available experimental data. It is true that Weber's experiments have not been confirmed, and indeed the first results from three or four experimental groups make it appear more probable that Weber's interpretation of his data is mistaken than that it is correct; but I do not think that experimenters working in the field have claimed this was a definite conclusion yet, and it seems rather premature for the Nature reporter to assume it and incorporate it so strongly in the title of his article.

As the report mentions a review which I gave at Oxford of the current experimental situation, I think I should point out that some of the statements which might appear to be attributed to myself are inaccurate and do not accord with my own views. For example, it is reported that all gravitational wave detectors are cooled to reduce thermal effects-when, although cooled detectors are being built, few, if any, are in operation. And I do not think that the conclusion is inescapable that Weber has not detected gravitational waves. Experiments in this field are long and difficult, and although one may speculate about the probable outcome I think it is too early to make definite conclusions at this stage.

In several places in this article, including the report of the theoretical discussion, I feel there are slight inaccuracies which, although small in themselves and probably accidental, do give an overall impression which may not help the research and may indeed unnecessarily hurt some of the persons involved. Although research on gravitational radiation is of a type which may, or may not, uncover new and unpredicted phenomena, I do not think it helps to overdramatize some aspects of the situation when what is required is patient experimental work together with careful interpretation.

$$
\begin{aligned}
& \text { Yours faithfully, } \\
& \text { R. W. P. DREver }
\end{aligned}
$$

Department of Natural Philosophy, Glasgow University, Glasgow G12 8QQ

\section{The Mind Diseased}

Sir,-Dr Thomas S. Szasz (Nature, 242, 305 ; 1973) writes that, strictly speaking, " . . . disease or illness can affect only the body. Hence there can be no such thing as mental illness". Thus he assumes that mental and bodily functions can be clearly separated, and that the mind is something apart from the body. This appears untenable in the light of modern biology ; the mind cannot be divorced from the organism as a whole. Dr Szasz appears further to say-although I wonder whether he really means it-that "mental patients", who suffered from no recognizable bodily illness, were generally and properly considered to be fakers and malingerers, until Charcot, Janet, and Freud led us astray with the concept of mental illness. I believe that Dr Szasz is wrong, both philosophically and historically.

No doubt many patients in the past were considered malingerers. Before the functions of the thyroid were understood, for instance, victims of hyperthyroidism or myxoedema were probably often placed in this category. Our knowledge of the finer details of the working of the brain is still rudimentary; the psychiatrist, dealing with a patient who is suffering agonizing distress, may not be able to put his finger on any objectively detectable abnormality in the patient's nervous system or hormonal balance. Are we therefore to say that the patient is not really ill, because no physical or chemical test is yet available, to be correlated with the symptoms? Does illness become real when someone discovers such a test, although it was unreal before?

The idea that nobody before Charcot believed in the reality of mental illness is untenable. Consider, for instance, the cry of Macbeth to the doctor who is treating Lady Macbeth: "Canst thou not minister to a mind diseased?" In this case, certainly, the doctor was helpless, but it is obvious that both Shakespeare and his audience believed in the reality of mental illness.

One famous eighteenth century patient, William Pitt, Earl of Chatham, suffered from occasional manic episodes and from several long periods of terrible depression, when he was completely incapacitated for many months at a time. During one such period (1767-68) Pitt was nominally Prime Minister; he begged George III to let him resign, because he was ill, and the King finally and reluctantly granted his request. Pitt's physician, Anthony Addington, certainly considered the depression as an illness; his major therapeutic approach was to encourage the development of attacks of gout, a disease to which Pitt was also subject. This was perhaps the eighteenth century equivalent of shock therapy. In any case, both Pitt and his doctor regarded these depressions as real illnesse ${ }^{1}$.

Dr Szasz proposes that all those who commit crimes should be dealt with by criminal law. Perhaps; but there is a difference between the man who kills another to get his money, and one who kills because he believes that his victim was trying to destroy him by evil magic. Perhaps both should be tried by the same judicial procedure, but surely the sentencing of the criminal should take the particular circumstances into account.

I share the concern of Dr Szasz over the outrages inflicted on many patients confined in mental hospitals against their will. A campaign against such crueity and injustice is entirely in order, but I believe that it will have a better chance of success if it is not entangled with a highly dubious philosophical outlook.

Yours faithfully,

JOHN T. EDSALL

\section{Biological Laboratories,}

Harvard University,

16 Divinity Avenue,

Cambridge, Massachusetts 02138

1 Tunstall, Brian, William Pitt, Earl of Chatham (Hodder and Stoughton, London, 1938). 